\title{
Renal Disease among HIV Positive Patients in Senegal
}

\author{
Khodia Fall ${ }^{1 *}$, Mouhamadou Moustapha Cissé1, Ahmed Tall Lemrabott1 ${ }^{1}$ Maria Faye1, \\ Mouhamed Cherif Dial'2, Atoumane Faye ${ }^{3}$, Seynabou Fall ${ }^{3}$, Moustapha Faye', Alex Keita1, \\ Mansour Mbengue ${ }^{1}$, Seynabou Diagne1, Niakhaleen Keita1, Bacary Ba1, Abdou Niang1, \\ Boucar Diouf ${ }^{1}$, El Hadji Fary Ka ${ }^{1}$
}

\author{
${ }^{1}$ Nephrology and Hemodialysis Department CHU Aristide Le Dantec, Dakar, Senegal \\ ${ }^{2}$ Cytology and Histopathology Department, Grand-Yoff General Hospital, Dakar, Senegal \\ ${ }^{3}$ Internal Medicine Department CHU Aristide Le Dantec, Dakar, Sénégal \\ Email: ^fallkhodia@yahoo.fr
}

How to cite this paper: Fall, K., Cissé, M.M., Lemrabott, A.T., Faye, M., Dial, M.C., Faye, A., Fall, S., Faye, M., Keita1, A., Mbengue, M., Diagne, S., Keita, N., Ba, B., Niang, A., Diouf, B. and Ka, E.H.F. (2017) Renal Disease among HIV Positive Patients in Senegal. Open Journal of Nephrology, 7, 101-106.

https://doi.org/10.4236/ojneph.2017.74012

Received: October 14, 2017

Accepted: December 26, 2017

Published: December 29, 2017

Copyright $\odot 2017$ by authors and Scientific Research Publishing Inc. This work is licensed under the Creative Commons Attribution International License (CC BY 4.0).

http://creativecommons.org/licenses/by/4.0/ c) (i) Open Access

\begin{abstract}
Introduction: Renal disease (RD) in human immunodeficiency virus (HIV) infection is a decisive turning point in the development and prognosis of this disease. In Africa, the prevalence varies between $2.5 \%$ and $48.6 \%$. In Senegal, little data are available in the literature. The objective of our study was to describe the epidemiological, clinical, paraclinical, therapeutic and progressional aspects in patients living with HIV (PLWHIV). Patients and methods: This was a retrospective, descriptive and analytical study carried out over a 10-year period in the Department of Internal Medicine and Nephrology at the Aristide Le Dantec Hospital in Dakar, Senegal. We included all 15-year old and above PLHIV with available CD4 count and viral load. Results: Out of 248 PLHIV, 32 had kidney disease (KD), which means a hospital prevalence of $12.9 \%$. The mean age was $51.22 \pm 10$ years (extremes of 36 and 77 years) with a sex ratio (male/female) of 1.28. Renal signs were dominated by glomerular nephropathy syndrome. It was present at $80 \%$. Tubulo-interstitial nephropathy syndrome and chronic uremic syndrome accounted for $6.25 \%$ and $3.1 \%$ of cases, respectively. Renal function Impairment was present in 21 patients with 18 cases of acute kidney injury (85.7\%) and 3 cases of chronic renal failure (14.3\%), including 2 in stage 5 of chronic kidney disease. Renal biopsy (RB) was indicated and performed in $20(62.5 \%)$ patients with glomerular signs in 12 patients $(60 \%)$. Glomerular lesions were dominated by focal and segmental glomerulosclerosis (FSGS) in 6 cases, membraneous nephropathy (MN) in 4 cases and minimal change disease (MCD) in 2 cases. Tubulo-interstitial and vascular lesions were present in $45 \%$ and $12.5 \%$ of cases, respectively. In highly active antiretroviral therapy (HAART), 12 (37.5\%) patients had total remission, $9(28.12 \%)$ had partial remission. One $(3.12 \%)$ death from severe meta-
\end{abstract}


bolic acidosis on chronic renal failure was deplored. Conclusion: This study illustrates the high prevalence of RD in PLHIV in our exercise context.

\section{Keywords}

Kidney Disease, HIV, HIVAN, Senegal

\section{Introduction}

Human immunodeficiency virus (HIV) infection is a chronic systemic disease that exposes to many complications including renal disease [1]. Renal disease is frequently encountered in HIV-infected patients and is a critical turning point in the prognosis and progression of these patients. It is linked to the viral infection itself; complications or treatment. The most commonly recognized histological translation is HIV-associated nephropathy (HIVAN). Sub-Saharan Africa counts for nearly 60 per cent of the world's HIV-infected population according to the World Health Organization (WHO) estimations in 2015. Epidemiological data on the overall prevalence of renal disease in this region vary between $2.5 \%$ and $48.6 \%$ of cases [2] [3]. In Senegal, $0.7 \%$ of the general population is infected with HIV. However, the prevalence of renal disease in this population remains unknown. This study was used to determine the epidemiological, clinical, paraclinical, therapeutic and progressional profiles of renal disease in PLHIV.

\section{Patients and Methods}

This was a retrospective descriptive and analytical study over a 10 -year period from $1^{\text {st }}$ of January 2004 to $31^{\text {st }}$ of December 2014. We included all 15-year old and above PLHIV, hospitalized or followed in the departments of internal medicine and nephrology of the Hospital Aristide Le Dantec of Dakar (Senegal). For each PLHIV included, socio-demographic, clinical, paraclinical, therapeutic and progressional data were identified. The studied parameters were renal function, $24 \mathrm{hrs} \mathrm{Pu}$, ultrasound of the kidneys and the urinary tract and RB. Viral load and $\mathrm{CD} 4$ count were recorded. Kidney disease was defined according to the KDIGO 2013 criteria [4]. The data collection was done manually using on study record forms. Data entry was done using Sphinx Plus2 software Lexica Edition. All the data were statistically analyzed using the R version R.3.2 software. The qualitative variables were presented as a percentage and the quantitative variables were presented as means, more or less the standard deviation or with a minimum and a maximum. The analytical study was done with cross-tabulations. To compare the frequencies, the KHI 2 test or the Fisher test were used. The difference was statistically significant for " $p$ " value $<0.05$. The local ethics committee gave its approval for carrying out this study.

\section{Results}

Two hundred and forty-eight (248) PLHIV were collected during the study pe- 
riod. Thirty-two (32) patients had renal function impairment, which means a hospital prevalence of $12.9 \%$. Among the patients with renal function impairment, there were 18 men and 14 women, a sex ratio (male/female) of 1.28 . Their mean age was $51.22 \pm 10.88$ years. The predominant age group was 40 to 60 years with a prevalence of $40.6 \%$ (Figure 1). Renal signs were dominated by glomerular nephropathy syndrome (80.8\%). Tubulo-interstitial nephropathy syndrome was noted in $9.3 \%$ of cases. Laboratory results showed a mean creatinine level of $52.75 \mathrm{mg} / \mathrm{l} \pm 9.28 \mathrm{mg} / \mathrm{l}$ [14.62 - $134 \mathrm{mg} / \mathrm{l}]$. Twenty-one (21) patients had renal function Impairment (RfI), which makes 65.6\%. Eighteen (18) patients had an AKI (85.7\%) and three patients (14.3\%) had CRF. Fluid and electrolytic disorders were represented by hyponatremia (25\%), hypokalemia (12.5\%) and hyperkalemia (18.75\%). All patients had HIV type1 profile. The average CD4 count was $204 / \mathrm{ml} \pm 12.8$ cells/ml with extremes of 20 and $614 / \mathrm{ml}$. Sixteen patients $(50 \%)$ were already on stage 3 of the $\mathrm{WHO}$ at the time of diagnosis, 10 patients $(31.3 \%)$ on stage 2 and 6 patients $(18.8 \%)$ on the AIDS disease stage. Proteinuria was present in 18 patients (56.25\%) with the mean value of 3.3 $\mathrm{g} / 24 \mathrm{~h} \pm 7.11 \mathrm{~g} / 24 \mathrm{~h}$. Thirteen (13) patients; with a prevalence of $72 \%$ had glomerular proteinuria. Aseptic leukocyturia was present in 2 patients (6.25\%) and microscopic hematuria in 3 patients $(9.37 \%)$. Morphologically, kidney size was normal in $84.3 \%$ (27 cases), increased in 6.25\% (2 cases) and decreased in $9.37 \%$ (3 cases). The average size was $108.34 \mathrm{~mm}(79-126 \mathrm{~mm})$ on the right and 108.13 $\mathrm{mm}(80-123 \mathrm{~mm})$ on the left. Parenchyma-sinus differentiation was good in $78.1 \%$ patients (27 cases), fair in $6.25 \%$ ( 2 cases), and poor in $15.6 \%$ (6

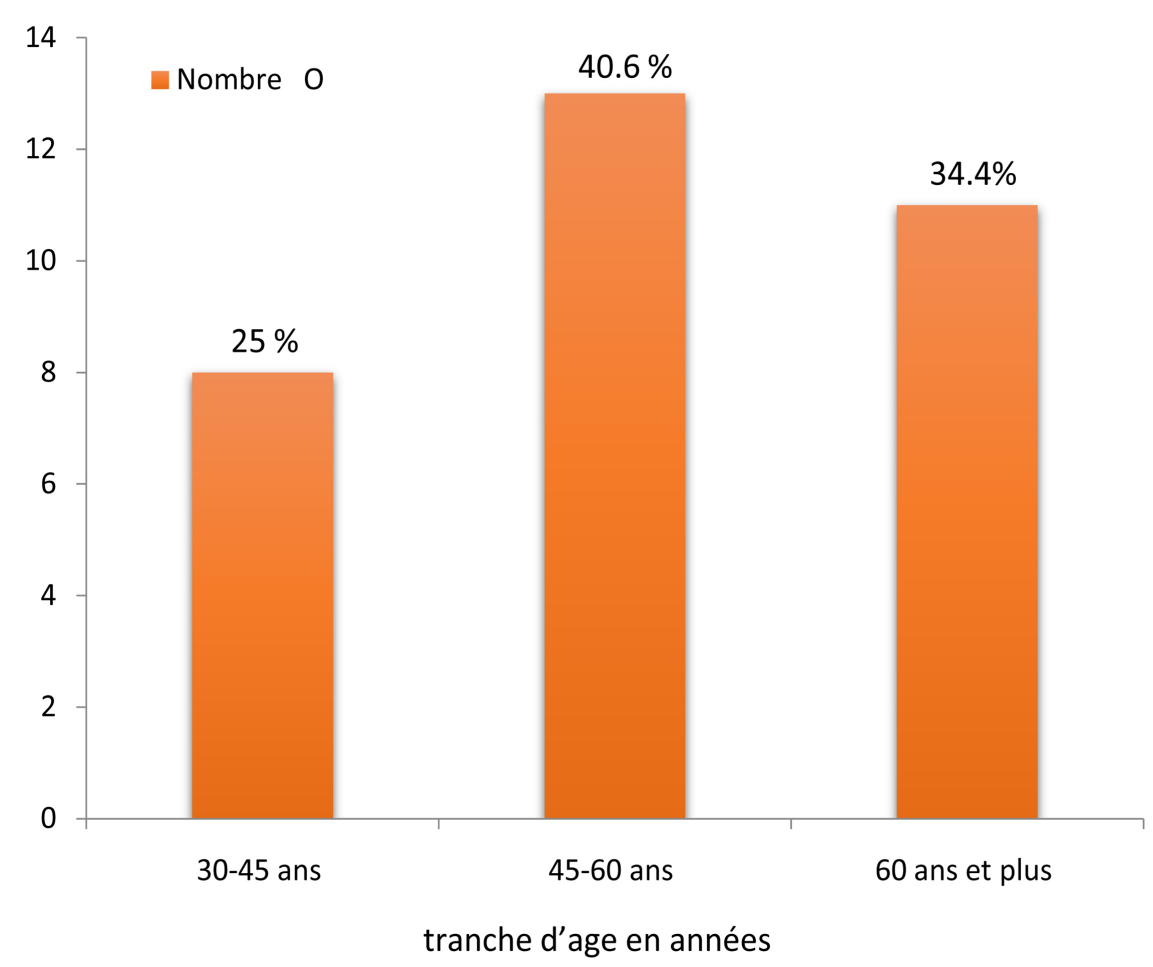

Figure 1. patient distribution by age. 
cases). On histology, RB was performed in 12 patients all with glomerular nephropathy syndrome. Non collapsing FSGS was present in 4 patients (33\%), MEN in 4 patients (33\%) and MCD in 2 patients (17\%). Two patients (17\%) had HIV-associated nephropathy (HIVAN) lesions. All biopsy patients had tubulo-interstitial lesions either alone or in combination with other lesions. Secondary tubulo-interstitial lesions from drug toxicity of ARVs were noted in 9 patients (45\%). Thrombotic microangiopathy and nephroangiosclerosis were the main vascular lesions found (Table 1). In bivariate analysis, the occurrence of renal disease was associated with decreases in CD4 $(\mathrm{p}=0.0052)$ and initiation of first-line antiretroviral therapy $(\mathrm{p}=0.0127)$.

\section{Discussion}

The prevalence of renal disease in HIV varies between $2 \%$ and $48 \%$ according to the series [2] [5] [6]. In Senegal, despite the low prevalence of HIV infection, we report an overall prevalence of $12.9 \%$ of renal function impairment. In Europe, the authors reported a prevalence varying between $2 \%$ and $30 \%$ [6] [7] [8]. In Africa, prevalence also varied between $6 \%$ and $48 \%$, with a clear increase over the past 10 years. South Africa, which is a country with a high HIV endemicity, encompasses a $\mathrm{RD}$ prevalence of $6 \%$ [9], which is relatively low compared to our study. However, in most African series, the prevalence is higher than ours; up to 48.5\% in Uganda [10] [11]. This could be explained by the high prevalence of HIV infection and the difficulty of access to treatment in these areas. RfI was the most frequent complication in HIV infection. It was present in our study in 21 patients, which means $65.6 \%$. We noted $85.7 \%$ of AKI and $14.3 \%$ of CRF, including 2 in stage 5 of chronic kidney disease and 1 in stage 3 . In the literature, HIV prevalence varies between $1 \%$ and $54 \%$ depending on the series [12] [13] [14]. Histologically, FSGS is the most common glomerular lesion in our series. It was found in 6 patients (50\% of cases) including 4 (66.7\%) conventional FSGSF and $2(33.3 \%)$ collapsing FSGS commonly known as HIVAN. We report to our

Table 1. Summary of various histological lesions foun.

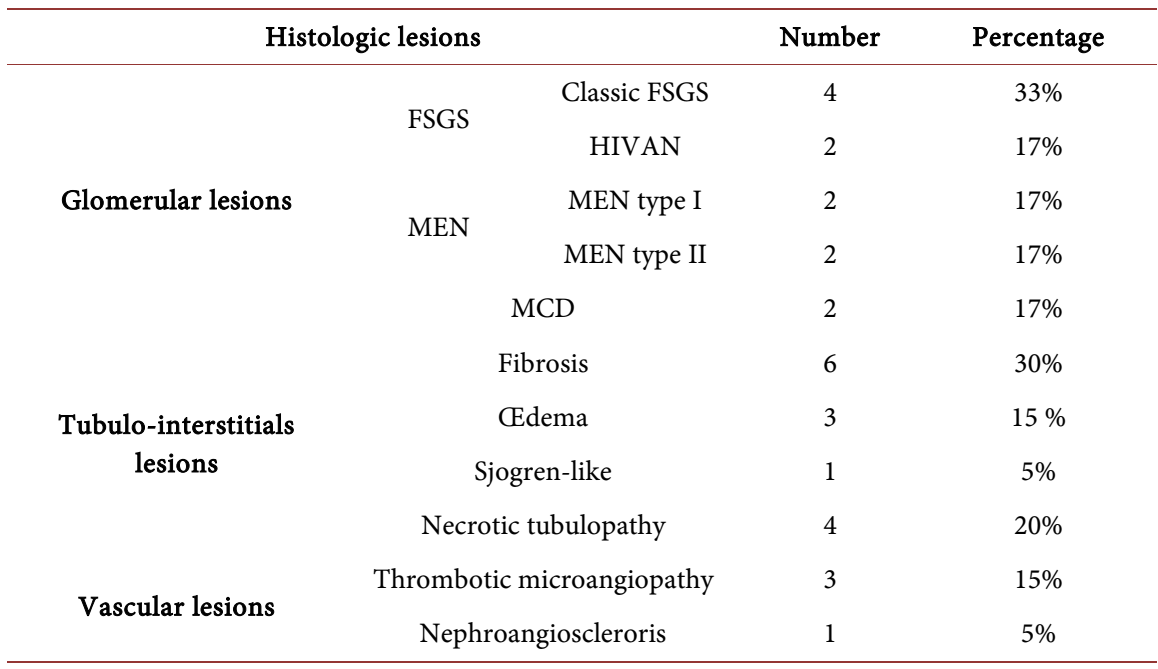


knowledge the first three cases of HIVAN in Senegal. The prevalence of HIVAN varies according to the studies (between $14.1 \%$ and 57\% of cases in Europe [15] [16], around $6.9 \%$ of cases [17] in the USA and 5.8\% of cases in India [14]. In Thailand, no case of HIVAN has been objectivated by Kearkiat P [9]. MEN and MCD lesions were found in 33\%, 3\% and $16.7 \%$ of our study population, respectively. These lesions are rarely described in the literature. Other glomerular lesions described in HIV, include membranoproliferative glomerulonephritis (MPGN), acute glomerulonephritis (AGN), amyloidosis, lupus-like, immune complex glomerulonephritis or crescentic glomerulonephritis (CGN) have not been found in our study population. All our patients had tubulo-interstitial lesions. This could be explained by the massive use of phytotherapy in our country. To this phytotherapy are added the toxicity of the ARV and the interstitial lesions directly related to HIV. Indeed, 9 patients out of 20 biopsied (45\%) had a renal toxicity related to the ARV treatment. Tubulo-interstitial lesions secondary to ARV treatment are described in the literature: 2 cases by Bentata [18] and 13 cases $(27.1 \%)$ by Zaidan [19]. Thrombotic microangiopathy lesions were described in HIV with the highest frequency found by Abraham B, which reported 14 cases of MAT [20]. In our series, it was demonstrated in 3 patients or $15 \%$ of the histological lesions.

On the progression aspect, 21 (65.62\%) patients had a favorable outcome with $57 \%$ total remission (12 patients) versus $43 \%$ partial remission ( 9 patients). Eight patients (25\%) progressed to $\mathrm{CKD}, 3$ of them at the end stage requiring chronic dialysis. Three (3) patients (or 9.37\%) died, two of which were directly related to HIV infection and one to chronic kidney disease.

\section{Conclusion}

RD still remains common among PLHIV in our country. It is an important morbidity and mortality factor. Sub-Saharan African countries in general and Senegal in particular, should put in place all needed human and technical resources to the fight against this scourge.

\section{References}

[1] Criton, C. (2009) Renal Involvement in HIV Infection. AIDS Science. Scientific News on HIV Infection. http://sidasciences.inist.fr/Nephropathy\%20and\%20HIV\%20infection

[2] Ahmed-Moussa, A. (2000) Renal Damage in the Course of HIV Infection at the G-Point National Hospital. Ph.D. Dissertation, Bamako.

[3] Han, T.M., Naicker, S., Ramdial, P.K. and Assounga, A.G. (2006) A Cross-Sectional Study of HIV-Seropositive Patients with Varying Degrees of Proteinuria in South Africa. Kidney International, 69, 2243-2250. https://doi.org/10.1038/sj.ki.5000339

[4] Kidney Disease Improving Global Outcomes (KDIGO) (2012) Clinical Practice Guideline for the Evaluation and Management of Chronic Kidney Disease. Kidney International Supplements, 3, 5-14.

[5] Attolou, V., Bigot, A., Ayivi, B. and Gninafon, M. (1998) Renal Complications Associated with Human Acquired Immunodeficiency Virus Infection in a Population 
of Hospital Patients at the National Center Hospital in Cotonou. Health, 8, 283-286.

[6] Nochy, D., et al. (1997) Renal Involvement in HIV Infection. La Presse Médicale, 26, 91-95.

[7] Izzedine, H. (2009) Renal Pathology in the Course of HIV Infection. Letter from the Infectiologist, 24,146-156.

[8] Kearkiat, P., Sophon, N., Saowanee, Y., Pongsak, W., Kriang, T. and Visith, S. (1995) Renal Pathology and HIV Infection in Thailand. American Journal of Kidney Diseases, 33, 282-286.

[9] Fabian, J., Naicker,S., Venter, W.D., Baker, L., Naidoo, S. and Paget, G.W. (2009) Urinary Screening Abnormalities in Antiretroviral-Naive HIV-Infected Patients and Implication for Management-A Single-Center Study in South Africa. Ethnicity \& Disease, 19, 80-85.

[10] Fabian, J. and Naicker, S. (2009) HIV and Kidney Disease in Sub-Saharan Africa. Nature Reviews Nephrology, 5, 591-598. https://doi.org/10.1038/nrneph.2009.141

[11] Gregory, M., Lucas, G.M., Clarke, W., Kagaayi, J., et al. (2010) Kidney Function in a Community-Based Cohort of HIV-Infected and HIV Negative Individuals in Rakai. Uganda. Journal of Acquired Immune Deficiency Syndromes, 55, 491-494. https://doi.org/10.1097/QAI.0b013e3181e8d5a8

[12] Pakara, N.M. and Sumail, E.K. (2012) Anatomopathological Features of Renal Disease in Sub-Saharan Africa: A Synthetic Review of Data from the Democratic Republic of the Congo. Annals of Diagnostic Pathology, 32, 40-52.

[13] Shriganesh, R.B., AmitNagarik, A., Gopal Kishan, A. and Anuradha, S. (2008) HIV and Spectrum of Renal Disease. Indian Journal of Transplantation, 2, 25-31. https://doi.org/10.1016/S2212-0017(12)60012-4

[14] Struik, G.M., Den Exter. R.A., Munthali, C., Chipeta, D., Osterhout, J.G. and Nouwen, J.L. (2011) The Prevalence of Renal Impairment among Adults with Early HIV Disease in Blantyre, Malawi. International Journal of STD \& AIDS, 22, 457-462. https://doi.org/10.1258/ijsa.2011.010521

[15] Isnard, B.C., Rouvier, P., Tezenas du Montcel, S., Fernandes, P.F., Sonikian, M., Tourret, J., et al. (2013) Renal Histology and HIV Infection: And If Vascular Lesions Condition the Renal Prognosis. Nephrologie \& Therapeutique, 9, 320-360.

[16] Tourret, J., et al. (2009) Nephropathies Encountered during Infection with Human Immunodeficiency Virus (HIV). Nephrologie \& Therapeutique, 5, 576-591.

[17] Vahakh, S., Srinivasan, R., Borucki, M., Grady, J., Mike Hollander, P.H.W. and Ahuja, T.S. (2000) Prevalence of HIV-Associated Nephropathy in Autopsies of HIV-Infected Patients. American Journal of Kidney Diseases, 5, 884-888.

[18] Bentata, P.M., Buchet, P. and Jarousse, B. (1993) HIV Infection and Renal Disease: Study of 16 Cases. Internal Medicine Review, 14, 463.

[19] Zaidan, M., et al. (2011) Diversity of Nephropathies in HIV-Infected Patients and Interest in Urinary Protein Profile as a Predictive Tool for Histological Lesions. Nephrologie \& Therapeutique, 7, 34.

[20] Abraham, B., Baud, O., Bonnet, E., Roger, P.M., Chossat, I., Merle, C. and Reynes, J. (2001) Thrombotic Microangiopathy in HIV Infection: A Retrospective Study Carried out in the Infectious Diseases Departments of Southern France. Pres Med, 30, 581-585. 